\title{
Propostas para o Atendimento às Pessoas Surdas em Serviços de Governo Eletrônico
}

\author{
Sylvana Karla S. L. Santos ${ }^{1}$, Núbia Flávia O. Mendes ${ }^{1}$, Queila Pahim da Silva ${ }^{1}$ \\ ${ }^{1}$ Instituto Federal de Brasília - Campus Brasília - DF - Brasil. \\ \{sylkarla, nubiaflavia2, quepahim\}@gmail.com
}

\begin{abstract}
This article discusses access to information on Brazilian egovernment sites through Information and Communication Technologies, analyzes the importance of serving Brazilian Deaf people in their first language, the Brazilian Sign Language - Libras, and presents proposals to adapt and provide the access offered to citizens based on pages with a broader perspective.

Resumo. Este artigo discute sobre o acesso à informação em sites do governo eletrônico do Brasil por meio das Tecnologias da Informação e Comunicação, analisa a importância do atendimento às pessoas Surdas brasileiras em sua primeira língua, a Língua Brasileira de Sinais - Libras, e apresenta propostas para adequar e oportunizar a oferta de serviços aos cidadãos, a partir de páginas e conteúdos mais amplos.
\end{abstract}

\section{Introdução}

O acesso aos serviços de governo eletrônico depende, basicamente, da disponibilidade de tecnologias, como um dispositivo smartphone ou computador e da conexão à internet. De posse desse conjunto básico, todo cidadão tem ao seu alcance alguns benefícios, a exemplo de facilidade de organizar e enviar a declaração do imposto de renda, realizar inscrição em seleções e concursos públicos, entre outros.

Governo eletrônico (e-Gov) inclui o uso de TIC para a concretização de objetivos governamentais de forma a aumentar a eficiência dos recursos públicos e facilitar a participação dos cidadãos por meio da democratização para o acesso aos serviços e informações públicas [Cgi.br 2019].

Nesse sentido, o processo de transformação digital tem avançado e permitido que mais pessoas acessem a informação e tenham suas necessidades atendidas em um curto espaço de tempo, sem a exigência de ter que sair de casa e se deslocar, levando à melhoria de vida dos que residem e trabalham no país ${ }^{1}$. No entanto, a transformação digital de serviços de governo eletrônico não se resume à tecnologia e depende, entre outros fatores, da comunicação com o cidadão, que é o usuário [Monteiro 2020].

Para ter acesso a determinados serviços é necessário, além de dispor das tecnologias, saber utilizar com eficiência os serviços de governo. Isso significa que a experiência do usuário é um fator que precisa ser considerado. Caso contrário, o objetivo, para além da disponibilidade dos dados e do acesso à informação, pode não ser alcançado e a necessidade do usuário não será, consequentemente, atendida. Além disso, entre disponibilizar os dados e o usuário fazer uso efetivo existe uma lacuna que precisa ser avaliada [Macedo et al. 2020].

\footnotetext{
${ }^{1}$ Governo Digital. https://www.gov.br/governodigital/pt-br/transformacao-digital
} 
A consolidação dos dados em uma interface amigável pode auxiliar na futura compreensão, mas não garante que o usuário estará apto a fazer uso de um tipo de informação [Kaieski et al. 2014]. As diversas esferas de governo precisam estar alinhadas, integrando dados comuns para evitar falhas. Um exemplo recente é o cadastro para recebimento do auxílio emergencial, durante o enfrentamento à crise gerada pela pandemia do COVID-19, para dar assistência a trabalhadores autônomos e desempregados. Na ausência de um sistema de informações unificadas, foram identificados erros graves que induziram o pagamento indevido do benefício, assim como o não pagamento em casos comprovados [Senado Federal 2021].

No contexto da diversidade de cidadãos encontram-se as pessoas Surdas ${ }^{2}$, que acessam a informação e se comunicam, prioritariamente, por meio visual. Esse grupo tem a Língua Brasileira de Sinais - Libras como sua primeira língua e a língua portuguesa escrita como segunda língua [Gesser 2009], sendo este o principal usuário de serviços de governo eletrônico enfatizado neste estudo.

Após uma breve contextualização, este trabalho prossegue com os demais tópicos. A seção 2 trata da fundamentação teórica para a compreensão do objeto do estudo. A seção 3 descreve alguns trabalhos relacionados à temática dos serviços de governo eletrônico e ao usuário Surdo, publicados em pesquisas de Mestrado e Doutorado por autoras da Comunidade Surda do Brasil. A seção 4 propõe soluções para a melhoria de serviços e o atendimento ao público Surdo, finalizando com algumas considerações.

\section{Fundamentação teórica}

\subsection{Acesso à informação}

No campo da ciência, as pesquisas relacionadas às informações tiveram início na década de 1950, quando houve transformações significativas no âmbito industrial. O intuito era promover conhecimento acerca dos acontecimentos cotidianos a respeito do pólo industrial [Carvalho e Kaniski 2000]. Essas informações são representações organizadas, estocadas e distribuídas que exigem uma sistematização das informações, proporcionando à sociedade conhecimento [Barbosa 1986].

Segundo Marcondes [1994], o conhecimento é a chave fundamental para a libertação de circunstâncias negativas acometidas pela ignorância. Quando há busca por informações, significa o desejo de compreensão daquilo que se é pesquisado. Nesse sentido, as expectativas de busca por informações se concentram nos acontecimentos para a transformação de ações conscientes. Portanto, é necessário que todas as pessoas recebam com clareza as informações, partindo do pressuposto que serão ofertadas por meio da língua de seus receptores.

O acesso à informação oferecido pelo Estado, de forma clara, garante aos cidadãos os seus direitos respeitados, devendo ser repassadas de forma transparente com o objetivo de atender, orientar, informar, declarar e, dentre outras, prestar contas à sociedade [Brasil 2011]. Contudo, se as informações não são adequadas a toda população brasileira, os seus direitos estão sendo tomados pelo próprio Estado, nesse caso, inclui o direito dos Surdos.

\footnotetext{
2 A palavra "Surdo" grafada com "S" maiúsculo se difere de "surdo" por representar aqueles que lutam por seus direitos políticos, linguísticos e culturais e tem a Libras como primeira língua. Os surdos com "s" minúsculo optam por não ter a Libras como primeira língua. A diferenciação desses termos é utilizada por vários autores [Lane 2008 p. 284, Castro Júnior 2011 p. 12 e Santos 2019 p. 19].
} 


\subsection{Caracterização do usuário Surdo}

Anteriormente, explicitou-se a diferença entre "Surdo" - usuários da Libras - e "surdo" não usuário. É mister esclarecer também a diferença entre surdez como fator linguístico e cultural e como deficiência auditiva.

No modelo clínico-terapêutico, a surdez é vista como desvio, falta, falha ou imperfeição da audição e, por isso, é considerada uma deficiência [Skliar 1997]. O direcionamento dado por profissionais da saúde e da educação, neste caso, é a reabilitação oral e cura do problema auditivo, através de implantes cocleares e próteses, por exemplo. Já na abordagem socioantropológica, a surdez é uma diferença linguística e cultural, que deve ser respeitada e garantir identidade aos que fazem uso das línguas de sinais como forma de expressão e comunicação.

Não há uma língua de sinais universal, como nas línguas orais, ou seja, existe a Língua de Sinais Americana (ASL), Língua de Sinais Francesa (LSF), Língua de Sinais Portuguesa (LSP) e tantas outras. No Brasil, temos a Língua de Sinais Brasileira (Libras), reconhecida como meio legal de comunicação e expressão no país, através da Lei $\mathrm{n}^{\circ}$ 10.436/2002 [Brasil 2002] e regulamentada através do Decreto $n^{\circ}$ 5.626/2005 [Brasil 2005], que também assegura o atendimento em serviços públicos nesta língua. Além da Libras, reconhecida legalmente como a primeira língua dos Surdos brasileiros, existe ainda a Língua de Sinais Kaapor - LSK, língua de Surdos indígenas [Vilhalva 2009].

Considerando o último levantamento do Instituto Brasileiro de Geografia e Estatística (IBGE), realizado em 2010, sobre o quantitativo de pessoas surdas, havia no país, cerca de 10 milhões de brasileiros com algum tipo de perda auditiva, o que representava 5\% da população [IBGE 2010]. Como este Censo foi realizado há mais de 10 anos, acredita-se que este número seja bem maior, atualmente.

A perda auditiva, conforme a Organização Mundial da Saúde (OMS), caracterizase pela lesão de qualquer parte das vias auditivas, o que faz com que o som não seja adequadamente transmitido para o cérebro e, por isso, a percepção de sua intensidade, medida em decibéis $(\mathrm{dB})$, é comprometida, sendo categorizada entre perda leve, moderada, severa e profunda, ou ainda, surdez leve, moderada, severa e profunda [ONU news 2020].

O usuário Surdo é, portanto, o indivíduo que tem total ausência de audição e não faz uso da língua falada ou escrita como forma de comunicação. Para este público que os normativos legais brasileiros garantem o uso, difusão e tradução e interpretação da Libras para o efetivo e amplo atendimento e institui o papel do Poder Público e das empresas, concessionárias e permissionárias de serviços públicos, a garantir o atendimento em Libras para as pessoas Surdas e com deficiência auditiva [Brasil 2002, Brasil 2005].

No atendimento por meio de páginas web é preciso, portanto, a utilização de diferentes ferramentas tecnológicas e, dessa forma, esta temática será abordada a seguir, bem como exemplos e propostas para direcionar uma melhor prestação desse serviço pelo governo eletrônico.

\subsection{Recursos tecnológicos}

Alguns recursos tecnológicos tornam possível a oferta de produtos e serviços acessíveis para pessoas Surdas. Estes recursos são comumente denominados Tecnologia Assistiva TA e visam atender diferentes necessidades dos usuários em contextos variados. A TA 
objetiva "promover a funcionalidade, relacionada à atividade e participação, de pessoas Surdas e pessoas com deficiência, incapacidades ou mobilidade reduzida, visando sua autonomia, independência, qualidade de vida e inclusão social" [Brasil 2009].

A Norma Brasileira 15290:2005, revisada em 2016, trata da acessibilidade em comunicação na televisão e descreve algumas diretrizes que devem ser consideradas para atendimento às necessidades individuais, segundo as recomendações do Desenho Universal, que norteia a concepção de produtos e serviços para serem usados por todas as pessoas, independente de suas idades e/ou capacidades [ABNT 2005]. Esta norma contempla as características de uso da janela de Libras e orienta para a melhor localização na tela, dimensões e contraste. Os benefícios da janela de Libras para o público Surdo merecem ser observados e não apenas cumpridos a partir de uma legislação.

Além da janela de Libras, os softwares conhecidos como tradutores automáticos podem ser utilizados para auxiliar na conversão de conteúdo de uma língua para outra, tanto no formato escrito quanto em áudio ou visual. Um exemplo mais comum desses softwares é o Google Tradutor que abrange uma variedade de idiomas orais e possibilita a tradução de textos e áudios de uma língua para outra.

Enquanto tecnologia assistiva, o VLibras é a plataforma mais conhecida pela Comunidade Surda, desenvolvida por uma equipe de pesquisadores da Universidade Federal da Paraíba e utilizada de forma mais ampla em páginas web do governo brasileiro $^{3}$. Este tradutor utiliza um avatar, que equivale a uma representação gráfica e animada do ser humano para realizar a tradução em Libras. A conversão da língua portuguesa para a Libras utiliza como base os conhecimentos da inteligência artificial (IA), considerando as necessidades da língua e a ênfase do personagem virtual em expressar movimentos facial e corporal.

Tradutores automáticos, a exemplo do VLibras, são usados como ferramenta para auxiliar a comunicação com o Surdo. No entanto, algumas pesquisas mostram que o uso do avatar não garante a acessibilidade à informação para o Surdo, visto que a compreensão da mensagem depende do contexto da informação [Mendes 2019, Santos 2019]. Além disso, os tradutores automáticos não contemplam satisfatoriamente todos os parâmetros da Libras, resultando na fragilidade dos resultados da significalização [Vieira et al. 2014]. Como exemplo, tem-se o termo 'laranja' que pode ser interpretado como 'cor laranja' ou 'fruta laranja' [Paraíba 2020]. A correta interpretação não deve ser feita de forma descontextualizada, pois cada significado tem um sinal em Libras diferente e, caso não esteja claro no contexto em que é usado, corre-se o risco do termo ser traduzido com a datilologia, que equivale a soletrar, letra por letra, o que não contribui para a compreensão.

\section{Trabalhos relacionados}

\subsection{Iniciativas acadêmicas}

Imaginemos um cidadão que busca um serviço de governo eletrônico e, embora tenha conhecimentos suficientes para ler e escrever, não encontra facilidade para compreender o conteúdo do texto apresentado que, muitas vezes, utiliza linguagem técnica, científica ou jurídica. Tal situação é mais comum do que podemos imaginar.

\footnotetext{
${ }^{3}$ Governo Digital. Disponível em: https://www.gov.br/governodigital/pt-br/vlibras
} 
Em pesquisa de mestrado, investigou-se a tradução das informações centrais em Libras de bulas e embalagens de medicamentos de uso comum a grande parte da população para tratar, por exemplo, dor de cabeça. A tradução requer a sequência de alguns passos importantes para que a informação seja efetivamente transmitida para o usuário Surdo. Concluiu-se que a adequação das informações na versão em Libras requer uma tradução funcional, concomitantemente com os aspectos linguísticos da Libras e culturais dos Surdos para aproximá-los das informações de modo claro e compreensivo [Mendes 2019].

O acesso linguístico adequado evita transtornos, aborrecimentos e consequências negativas aos usuários, especificamente aos Surdos, haja vista que, os ouvintes têm a possibilidade de tomar medicamentos de forma consciente devido ao acesso às informações estarem disponíveis na língua portuguesa. Contudo, os usuários Surdos tomam medicamentos de forma inconsciente, quando não adequados em Libras, levandoos até mesmo a óbito. Nesse viés, a tradução funcional demonstra a usabilidade e a funcionalidade das informações por meio da sinalização em Libras, legenda de palavras chaves, imagens representativas, plano de fundo e figurino condizentes com o conteúdo selecionado [Mendes 2019].

Todos os anos, uma considerável parcela dos cidadãos brasileiros precisa elaborar a declaração do Imposto de Renda. Ao buscar informações na página do Ministério da Economia, percebe-se o quanto é complexo encontrar com agilidade e clareza orientações básicas e que, muitas vezes, o usuário não consegue assimilar sem a ajuda de um profissional [Santos 2019]. Muitas páginas web disponibilizam a "barra de pesquisa", um recurso comumente localizado no canto superior direito da página. Porém, essa localização nem sempre é intuitiva ou se apresenta de forma padronizada na interface.

Ao adotar um padrão de disposição de determinada funcionalidade em uma página, supõe-se a preocupação com o alcance da Usabilidade, termo que surgiu a partir de padrões $\mathrm{ISO}^{4}$, em 1998, e que vem evoluindo ao longo dos anos. Usabilidade está relacionada a atingir objetivos com eficácia, eficiência e satisfação [Dias 2003]. Isso significa, por exemplo, que o usuário poderá encontrar, sempre que desejar, uma funcionalidade específica indicada por um símbolo (ícone) específico, o que facilita a navegação na página e auxilia de forma mais autônoma na busca da informação.

No contexto do atendimento aos Surdos em aeroportos, percebe-se que houve um avanço significativo em iniciativas de acessibilidade, diante da presença de totens e painéis que utilizam um software tradutor para promover a comunicação com este público [Bitelo 2019]. Essa tecnologia facilita o acesso à informação, a partir da interação visual do usuário para viabilizar sua autonomia durante o processo de embarque e desembarque no ambiente físico do aeroporto. Porém, cabe ressaltar a importância do atendimento humano quanto à capacitação que os funcionários das empresas devem adquirir, caso necessitem se comunicar com seus clientes que usam a Libras.

De forma presencial, a Central de Libras é uma iniciativa para atender o público usuário da Libras e que, comumente, funciona por agendamento prévio entre o Intérprete de Libras e o usuário ${ }^{5}$. Apesar de ser um empreendimento que visa acessibilidade na língua do usuário, vale lembrar que, devido ao atual isolamento social, a eficiência do

\footnotetext{
${ }^{4}$ ISO - International Organization for Standardization - https://www.iso.org/home.html

${ }^{5}$ Central de Libras do DF. http://www.sepd.df.gov.br/menu-sec/cil/
} 
serviço presencial fica comprometida. O processo de desenvolvimento não pode ser guiado basicamente pelas necessidades impostas pelo mercado, mas deve considerar aspectos relativos aos usuários [Sousa 2012].

\subsection{Iniciativas de órgãos públicos}

O Instituto Nacional de Surdos (INES) mantém em funcionamento a programação da TV INES $^{6}$, veiculada pela internet. Dentre os vários programas exibidos na página web, ressalta-se o 'Fica a Dica' que oferece informações em Libras sobre os principais documentos pessoais dos cidadãos brasileiros, como o título de eleitor, a certidão de óbito, a carteira de trabalho e o CPF. A partir de vídeos curtos, com duração média de quatro minutos, é possível ter acesso a informações importantes em Libras, além de legendas e áudio, atingindo, dessa forma, o público não surdo.

Outro programa exibido pela TV INES é o 'Brasil Eleitor' que tem o objetivo de auxiliar os cidadãos em suas decisões de foco no processo democrático de forma clara. Para isso, o programa conta com um intérprete de Libras em destaque e uma janela auxiliar com a exibição da reportagem relacionada ao assunto ${ }^{7}$. A intérprete de Libras ocupa um espaço maior na tela, uma vez que o foco é o usuário da Libras e este deve ser o principal beneficiado pela adoção desta configuração.

No contexto da educação pública da Rede Federal, um exemplo de iniciativa de acessibilidade para atendimento ao público Surdo na web é o sítio do Instituto Federal de Santa Catarina (IFSC) - Campus Palhoça. Esta unidade do IFSC é denominada "Campus Palhoça Bilíngue", por ser a primeira da Rede Federal de Educação Profissional e Tecnológica que atua e oferta cursos na modalidade bilíngue - Libras/Português. A página web da instituição serve como referência nacional para a Comunidade Surda por oferecer conteúdos essencialmente visuais, com imagens, vídeos em Libras e legenda, além de textos curtos e objetivos.

Visando o acesso às informações do poder legislativo, o site da Câmara dos Deputados disponibiliza o 'Dicionário de Libras - Termos político-legislativos', indicado para auxiliar o cidadão para a compreensão de termos específicos daquela instituição [Câmara $\mathrm{s} / \mathrm{d}$ ]. O dicionário contém uma lista de termos, em ordem alfabética, e que, em geral, são complexos para a maioria dos cidadãos. Ao disponibilizar em língua portuguesa escrita e também em Libras, a informação promove a inclusão não apenas do público Surdo, mas também de todo cidadão que busca conhecer o vocabulário utilizado nesse contexto.

Mais um produto direcionado à acessibilidade em Libras e desenvolvido por órgãos do governo é o 'Glossário Jurídico' do Supremo Tribunal Federal ${ }^{8}$ (STF). O material é composto pela série 'Direito em Libras', produzida em vídeos com áudio e legendas e que compõem uma iniciativa do Poder Judiciário voltada à inclusão social e à promoção da cidadania das pessoas usuárias da Libras. Novamente, ao tratar de aspectos jurídicos que, geralmente, possuem uma linguagem de difícil compreensão do cidadão, em geral, o conteúdo produzido promove a acessibilidade para uma parcela maior da população que busque esse conhecimento.

\footnotetext{
${ }^{6}$ TV INES. Programa Fica a Dica. disponível em: http://tvines.org.br/?cat=39

${ }^{7}$ TV INES. Programa Brasil Eleitor. disponível em: http://tvines.org.br/?p=14662

${ }^{8}$ STF - Glossário Jurídico. disponível em: https://www.youtube.com/watch?v=dAbs3W-DXCk
} 
Considerando essa diversidade de mídias possíveis, percebe-se que é viável atender a diferentes públicos e suas necessidades específicas. Para isso, o foco não deve ser generalizado apenas para o usuário da língua portuguesa escrita e sim, de forma mais ampla, deve-se ponderar também os usuários que são mais auditivos e aqueles que são mais visuais. Esse cenário nos leva a algumas propostas possíveis para oportunizar a construção de páginas e conteúdos mais amplos.

\section{Propostas possíveis para o atendimento ao Surdo}

Com base na literatura pesquisada e nas experiências apresentadas, serão descritas, a seguir, duas propostas, avaliadas como possíveis, e que visam facilitar o acesso à informação e o atendimento às necessidades do público Surdo aos serviços de governo eletrônico.

\subsection{Página do Ministério da Economia}

A primeira proposta faz referência ao portal da Receita Federal do Brasil ${ }^{9}$, vinculado ao Ministério da Economia. A partir da página principal, visualizamos um bloco na parte inferior direita intitulado "Meu CPF" que, ao ser acessado, direciona o usuário a uma página com o conceito de $\mathrm{CPF}$, descrito por meio de um texto em língua portuguesa. Logo abaixo do texto, são apresentados os "serviços em destaque", representados por blocos que direcionam para cada uma das quatro opções possíveis, sejam: inscrever no CPF, atualizar CPF, consultar CPF e obter cartão de CPF. A funcionalidade mouseover ${ }^{10}$, implementada para cada um dos blocos, alterna a imagem com fundo cinza claro para um texto com fundo escuro e fonte clara (Figura 1).

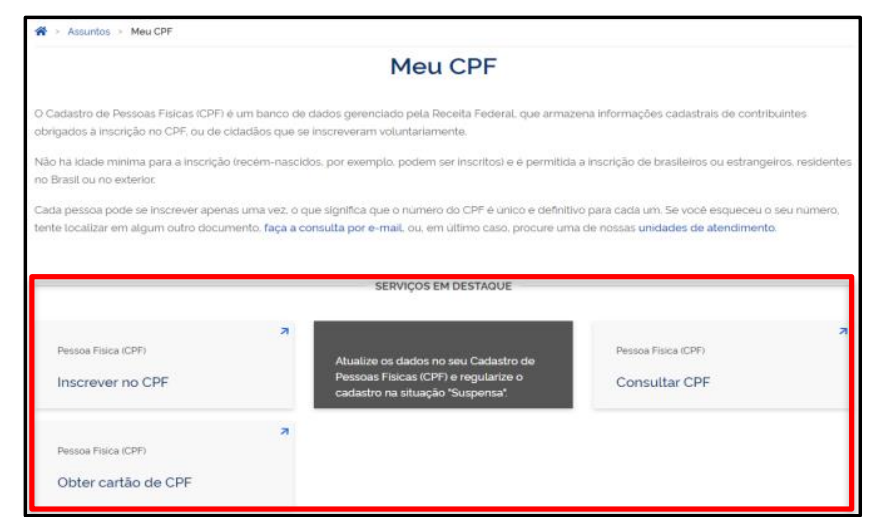

Figura 1. Página web da Receita Federal - Meu CPF. Fonte: capturado de Receita Federal $>$ Meu CPF ${ }^{11}$.

Observa-se que, para o público Surdo, essa alternância não acrescenta significado relevante à compreensão do conteúdo, pois permanece em língua portuguesa escrita. Além disso, apesar de o portal da Receita Federal oferecer a funcionalidade do software VLibras para auxiliar na conversão textual para a Libras, a tradução não se mostra possível para as informações textuais dos blocos mencionados, visto que, ao selecionar o texto de um determinado bloco, o avatar do VLibras não realiza a interpretação, pois não reconhece esse conteúdo como texto.

\footnotetext{
${ }^{9}$ Receita Federal do Brasil. Página principal. disponível em: https://www.gov.br/receitafederal/pt-br

${ }^{10}$ https://en.wikipedia.org/wiki/Mouseover

11 Receita Federal. Meu CPF. disponível em: https://www.gov.br/receitafederal/pt-br/assuntos/meu-cpf acesso em: 10 abr. 2021.
} 
A partir da dificuldade apresentada, uma proposta possível é incluir o ícone de "Acessibilidade em Libras" diretamente em cada bloco para que o público Surdo possa identificar a aplicabilidade. Esse ícone, representado por duas mãos sobrepostas e invertidas, foi idealizado em 2012 pela Universidade Federal de Minas Gerais ${ }^{12}$ e, desde então, é utilizado para indicar que o material ou evento possui acessibilidade em Libras.

A Figura 2 mostra o bloco "Inscrever no CPF" com a implementação visual da proposta descrita. Na prática, o usuário Surdo, ao visualizar o ícone "Acessibilidade em Libras", poderá reconhecer a funcionalidade e, ao clicar, será direcionado a um vídeo explicativo do serviço em destaque específico para ter acesso ao conteúdo em Libras. Dessa forma, a sugestão pode atender tanto às necessidades do usuário que utiliza a língua portuguesa escrita quanto do usuário Surdo.

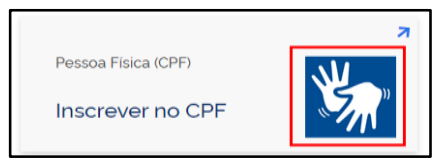

Figura 2. Proposta de acessibilidade em Libras para a página Meu CPF. Fonte: Adaptado de Receita Federal > Meu CPF.

Salienta-se que a página da Receita Federal já possui no menu superior opções de acessibilidade para ajuste de contraste e aumento do tamanho da fonte, assegurando adaptações para pessoas com deficiência visual. Esse conjunto de funcionalidades aproxima-se do conceito de Desenho Universal que visa atender diferentes necessidades e incluir o maior número de usuários.

\subsection{Página do Ministério da Saúde}

De forma semelhante, o portal do Ministério da Saúde também oferece o VLibras, cujo intuito é eliminar as barreiras para que "todas as pessoas possam perceber, entender, navegar e interagir de maneira efetiva com as páginas" [Brasil 2020].

A ferramenta, no entanto, disponibilizada para o acesso à tradução em avatar (Figura 3), apresentou falhas na conexão com o servidor e não completou o processo durante alguns testes realizados em abril de 2021. Após várias tentativas, quando encontrada a "tradução", esta se realizou de forma mecanizada, isto é, sinalizando palavra por palavra. Na maioria das vezes, o avatar utiliza a datilologia, ou seja, letra por letra, seguindo os padrões linguísticos da língua portuguesa.

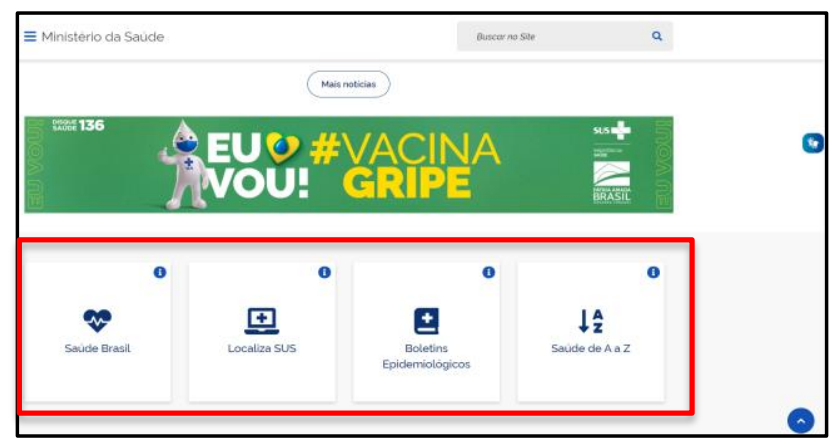

Figura 3. Página web do Ministério da Saúde - Mais notícias. Fonte: capturado de Ministério da Saúde ${ }^{13}$.

\footnotetext{
${ }^{12}$ Símbolo Acessível em Libras. Disponível em: https://www.ufmg.br/marca/libras/\#variacoes

${ }^{13}$ Ministério da Saúde. disponível em: https://www.gov.br/saude/pt-br acesso em: 12 abr. 2021.
} 
Ocorre que a datilologia não se adequa às necessidades linguísticas dos Surdos, que dispensam a oferta de tradução em avatar e continuam sem compreender as informações. Os tradutores em avatar precisam alcançar excelente desenvoltura quanto à contextualização, nos movimentos das mãos e do corpo, nas expressões faciais, na percepção cultural, dentre outros fatores que englobam as práticas tradutórias. A orientação, nesse caso, enquanto os avatares se aperfeiçoam, é colocar tradutores humanos, preferencialmente Surdos, para a identificação cultural, e que tenham experiências na tradução e na interpretação em Libras. Caso sejam tradutores ouvintes, devem ser participantes da Comunidade Surda e proficientes em tradução e interpretação em Libras [Mendes 2019].

A proposta de acessibilidade para este serviço toma como objeto a seção "Mais notícias" do portal do Ministério da Saúde que apresenta quatro blocos, localizados abaixo do banner da campanha de vacinação contra a gripe, conforme ilustrado na Figura 4. Cada um dos blocos possui um ícone de informação, comumente utilizado em Desenho Universal e simbolizado por um 'i' em cor azul, localizado no canto superior direito do bloco. Ao clicar neste ícone de informação, o conteúdo do bloco altera para o fundo cinza com fonte branca, implementando o contraste do conteúdo textual, de modo semelhante ao observado na página da Receita Federal, analisada anteriormente.

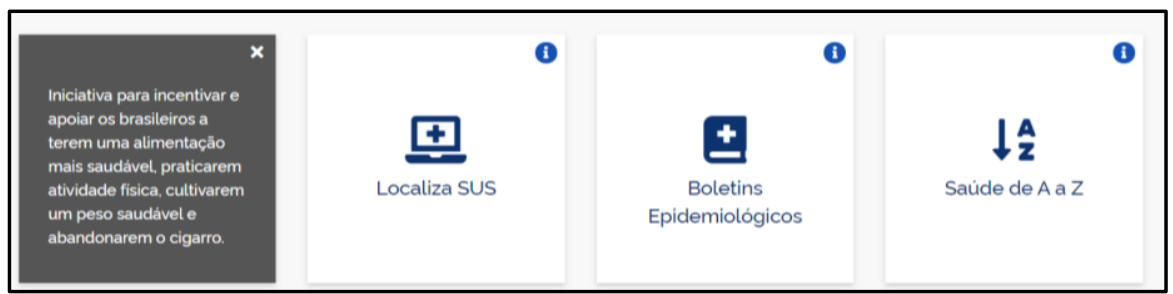

Figura 4. Recurso de transição de conteúdo com contraste.

Fonte: capturado de Ministério da Saúde > Mais notícias.

Para tornar o conteúdo do portal do Ministério da Saúde efetivamente acessível aos Surdos, sugere-se incluir o ícone de "Acessibilidade em Libras" logo abaixo do ícone informação (Figura 5). Dessa forma, ao clicar no novo ícone implementado, o usuário será direcionado ao conteúdo de um vídeo em Libras, com intérprete humano, que irá explicitar a informação referente à respectiva notícia, no caso, Saúde Brasil.

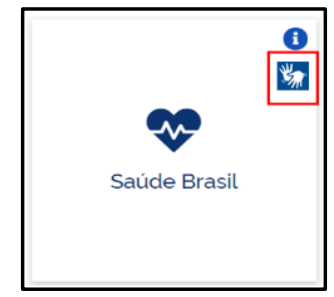

Figura 5. Proposta de acessibilidade para portal do Ministério da Saúde. Fonte: Adaptado do portal Ministério da Saúde > Mais notícias.

Considerando ambas as propostas apresentadas, ressalta-se ainda que é necessário que o tradutor humano corresponda aos processos tradutórios, de acordo com o texto de partida, que leve ao público Surdo clareza nas informações e se adeque a Cultura Surda. Dentre os requisitos citados por Mendes [2019], estão o figurino, plano de fundo, iluminação, imagens, legenda de palavras-chave, tradutor Surdo, conforme mostra a Figura 6. 


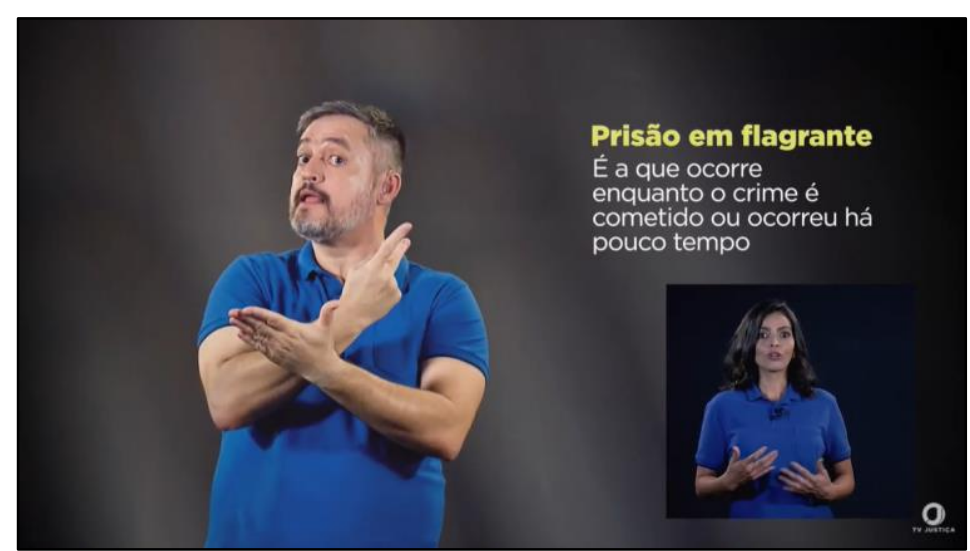

Figura 6. Recursos necessários para produção de vídeo em Libras. Fonte: YouTube. TV Justiça Oficial ${ }^{14}$.

As cores escuras do plano de fundo e do figurino atendem, também, às necessidades das pessoas Surdocegas com baixa visão. A legenda auxilia no processo de agilidade tradutória e na identificação de palavras que não possuem sinais, ao invés de recorrer a datilologia. As imagens contribuem no processo de aproximação cultural do público com o texto [Mendes 2019].

\section{Considerações Finais}

Diante das propostas trazidas por este trabalho, é importante destacar que nem sempre o alcance da acessibilidade está relacionado ao cumprimento às normas do $\mathrm{W} 3 \mathrm{C}^{15}$, que têm relação a ajustes no código da página, por exemplo. Para saber se o conteúdo da página está sendo corretamente acessado pelo usuário da informação, faz-se necessário questioná-lo, preferencialmente, em todas as etapas da construção do serviço (design participativo) e incluir o usuário fím para fazer parte do processo de desenvolvimento, etapa de testes e adequação da página a fim de garantir a acessibilidade do usuário ao produto ou serviço de governo eletrônico e contribuir para a consolidação do produto.

Importante considerar que, ao utilizar conteúdos em formato vídeo, a reprodução não deve sobrecarregar o equipamento do usuário, a ponto de tornar inviável o acesso à mídia. A produção desses conteúdos deve ser planejada para uma banda de acesso à internet que permita usufruir do serviço, deixando o conteúdo em formatos mais adequados em termos de reprodução.

Em relação aos avatares, considerando as limitações apresentadas, essa ferramenta indicaria útil se contemplasse todos os parâmetros da Libras, bem como as expressões faciais e corporais, a proficiência de forma contextualizada e aproximada a Cultura Surda. Partindo desse pressuposto, a tradução de portais do governo deve considerar o que melhor atende os seus usuários, especificamente os Surdos, e dispor de vídeos que sejam gravados com humanos, preferencialmente com tradutores e intérpretes Surdos. Para atender melhor o usuário, o processo de tradução deve contar também com a participação do público que deseja atender para que viabilize a melhor compreensão, com atenção também às variações regionais e à evolução constante da língua.

\footnotetext{
${ }^{14}$ TV Justiça Oficial. disponível em: https://www.youtube.com

${ }^{15}$ W3C ou World Wide Web Consortium. disponível em: https://www.w3c.br/
} 


\section{Referências}

ABNT. Associação Brasileira de Normas Técnicas (2005) NBR 15290. Acessibilidade em comunicação na televisão. $14 \mathrm{p}$.

Barbosa, W. V. (1986) Tempos pós-modernos. In: Lyotard, J-F. “O pós-moderno” Rio de Janeiro: J. Olympio, p. vii-xviii.

Bitelo, S. D. S. (2019) Como as companhias aéreas estão preparadas para atendimento de surdos em Santa Catarina: limites, avanços e desafios. 109f. Monografia (graduação) - Universidade Federal de Santa Catarina.

Brasil (2002) Congresso Nacional. Lei n ${ }^{\circ} 10.436$, de 24 de abril de 2002. Dispõe sobre a Língua Brasileira de Sinais - Libras e dá outras providências.

Brasil (2005) Presidência da República. Decreto no 5.626, de 22 de dezembro de 2005. Regulamenta a Lei $\mathrm{n}^{\mathrm{o}} 10.436$, de 24 de abril de 2002, que dispõe sobre a Língua Brasileira de Sinais - Libras, e o art. 18 da Lei n ${ }^{\circ} 10.098$, de 19 de dezembro de 2000.

Brasil (2009) Secretaria Especial dos Direitos Humanos. Comitê de Ajudas Técnicas. Tecnologia Assistiva. Brasília, DF: Presidência da República, 2009. Disponível em: http://www.galvaofilho.net/livro-tecnologia-assistiva_CAT.pdf Acesso em: 05 abr. 2021.

Brasil (2011) Congresso Nacional. Lei no 12.527, de 18 de novembro de 2011. Dispõe sobre o acesso à informação. Disponível em: http://www.planalto.gov.br/ccivil 03/ ato2011-2014/2011/lei/112527.htm Acesso em: 10 abr. 2021.

Brasil (2020) Ministério da Saúde. Governo Digital. Disponível em: https://www.gov.br/governodigital/pt-br/acessibilidade-digital Acesso em: 10 de abr. 2021.

Câmara dos Deputados (s/d) Acessibilidade na Câmara. Dicionário de Libras. Disponível em: https://www2.camara.leg.br Acesso em: 02 abr. 2021.

Carvalho, I. C. L., Kaniski, A. L. (2000). "A sociedade do conhecimento e o acesso à informação: para que e para quem" Ciência da Informação, 29(3).

Castro Júnior (2011) "Variação linguística em Língua de Sinais Brasileira: foco no léxico" 123 f. Dissertação (Mestrado em Linguística) - Universidade de Brasília.

Cgi.br. Comitê Gestor da Internet no Brasil (2019) "TIC Governo Eletrônico. Pesquisa Sobre o Uso das Tecnologias de Informação e Comunicação no Setor Público Brasileiro". São Paulo, 236p.

Dias, C. (2003) "Usabilidade na web: criando portais mais acessíveis". São Paulo: Alta Books, 296p.

Gesser, A. (2009) “Libras: que língua é essa?” São Paulo: Parábola Editorial, 88p.

IBGE (2010) Instituto Brasileiro de Geografia e Estatística. Censo Demográfico. Disponível em: https://www.ibge.gov.br Acesso em: 01 abr. 2021.

Kaieski, N., Villamil, M. e Oliveira, L. P. L. (2014) "Vis-Saúde: Sistema para Visualização de Dados Consolidados de Saúde Pública”. Workshop de Computação 
Aplicada em Governo Eletrônico (WCGE), 6., p. 17-24. Disponível em: https://sol.sbc.org.br/index.php/wcge/article/view/13355 Acesso em: 03 abr. 2021.

Lane, H. (2008) Do deaf people have a disability? In: Bauman, H-D. L. (Org.), “Open your eyes: deaf studies talking”. p. 277-292. Minneapolis: University of Minnesota.

Macedo, D., Barcelos, R., Bernardini, F., Viterbo, J. (2020) "Uma ferramenta para recomendação de visualização de dados governamentais abertos". Workshop de Computação Aplicada em Governo Eletrônico (WCGE), 8., p. 96-107. DOI: https://doi.org/10.5753/wcge.2020.11261

Marcondes, D (1994) A crise de paradigma e o surgimento da modernidade. In: Brandão, Z. (Org.). A crise dos paradigmas e a educação. São Paulo: Cortez, p. 16-29.

Mendes, N. F. O. (2019) "Informações centrais de medicamentos em Libras: tradução comentada para instituir o direito e o acesso linguístico dos Surdos na área da saúde". 243f. Dissertação (Mestrado em Tradução) - Universidade Federal de Santa Catarina.

Monteiro, L. F. (2020) "Desafios para a transformação digital no setor público brasileiro". Revista do TCU, 145, p. 4-8. Disponível em: https://revista.tcu.gov.br/ojs/index.php/RTCU/article/view/1662 Acesso em: 04 abr. 2021.

ONU news (2020) OMS alerta que perda de audição pode afetar mais de 900 milhões até 2050. Disponível em: https://news.un.org/pt/story/2020/03/1705931 Acesso em: 11 abr. 2021.

Paraíba (2021) “Governo do Estado da Paraíba. Educação. Inteligência artificial promove inovação na pesquisa paraibana". 24 jan. 2021. Disponível em: https://paraiba.pb.gov.br Acesso em: 03 abr. 2021.

Santos, S. K. S. L. (2019) "Usuários surdos e acessibilidade à informação em sítios web do governo brasileiro". 233p. Tese (Doutorado em Ciência da Informação) Universidade de Brasília.

Senado Federal (2021) Governo cobra devolução de auxílio emergencial pago indevidamente. Notícias. 2021. 12 jan. 2021. Disponível em: https://www12.senado.leg.br Acesso em: 28 mar. 2021.

Skliar, C. (1997) Uma perspectiva sócio - histórica sobre a psicologia e a educação dos surdos. In: Skliar, C. (Org.) "Educação \& exclusão: abordagens sócio-antropológicas em educação especial” p. 105-153. Porto Alegre: Mediação.

Sousa, M. R. F. (2012) O acesso a informações e a contribuição da arquitetura da informação, usabilidade e acessibilidade. Revista Informação \& Sociedade, João Pessoa, 22, p. 65-76.

Vieira, M. C., Corrêa, Y., Santarosa, L. M. C., Biasuz, M. C. V. (2014) "Análise de expressões não-manuais em avatares tradutores de Língua Portuguesa para Libras". Nuevas Ideas en Informática Educativa, Fortaleza, 10, p. 172-183.

Vilhalva, S. (2009) "Mapeamento das Línguas de Sinais emergentes: um estudo sobre as comunidades linguísticas indígenas de Mato Grosso do Sul”. Dissertação (Mestrado em Linguística) - Universidade Federal de Santa Catarina. 